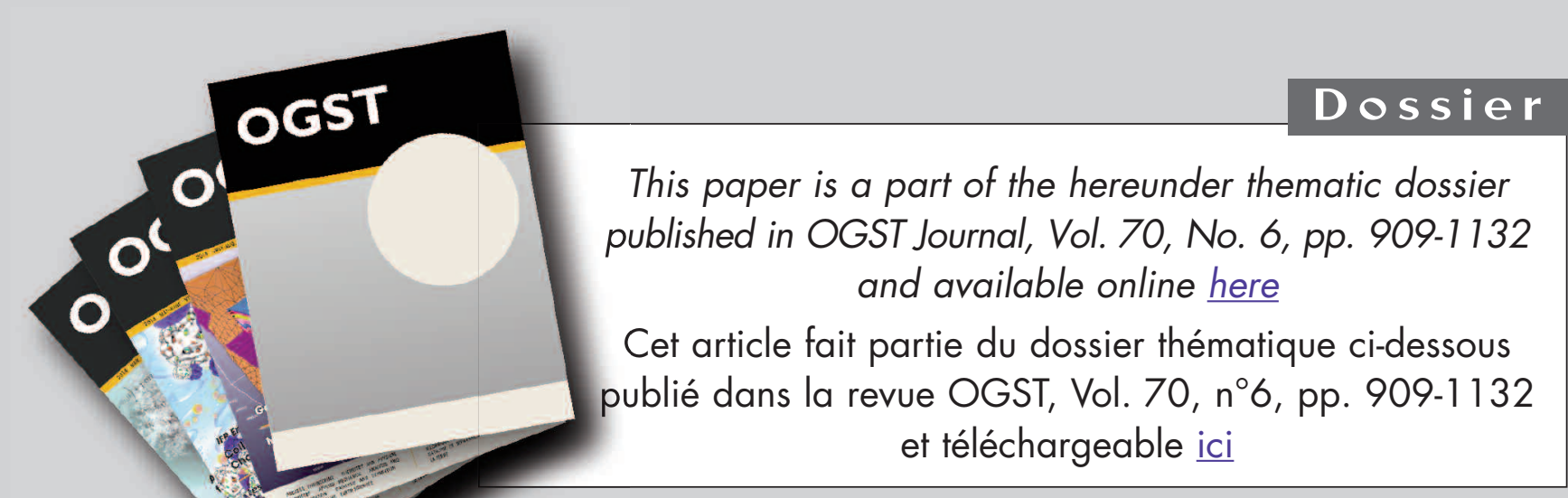

Oil \& Gas Science and Technology - Rev. IFP Energies nouvelles, Vol. 70 (2015), No. 6, pp. 909-1132

Copyright (C) 2015, IFP Energies nouvelles

909 > Editorial - Enhanced Oil Recovery (EOR), Asphaltenes and Hydrates Éditorial - EOR «récupération assistée du pétrole», Asphaltènes et Hydrates D. Langevin and F. Baudin

\section{ENHANCED OIL RECOVERY (EOR)}

917 > HP-HT Drilling Mud Based on Environmently-Friendly Fluorinated Chemicals Boues de forage HP/HT à base de composés fluorés respectueux de I'environnement

I. Henaut, D. Pasquier, S. Rovinetti and B. Espagne

931 > Effective Viscosity in Porous Media and Applicable Limitations for Polymer Flooding of an Associative Polymer

Viscosité effective dans des médias poreux et limites d'application de l'injection de polymères associatifs

P. Zhang, Y. Wang, Y. Yang, W. Chen and S. Bai

$941>$ Dynamic Gelation of HPAM/Cr(III) under Shear in an Agitator and Porous Media Gélification dynamique de HPAM/Cr(III) sous cisaillement dans un agitateur et en milieu poreux

Y. Haiyang, W. Yefei, Z. Jian, L. Peng and S. Shenglong

$951>$ Computer Modeling of the Displacement Behavior of Carbon Dioxide in Undersaturated Oil Reservoirs

Modélisation par ordinateur du comportement de déplacement du dioxyde de carbone dans des réservoirs d'huile non saturés

B. Ju, Y.S. Wu and J. Qin

$967>$ Predicting CO, Minimum Miscibility Pressure (MMP) Using Alternating Conditional Expectation (ACE) Algorithm

Prédiction de la pression miscibilité minimum (MMP) du CO en utilisant un algorithme basé sur l'ACE (Alternating Conditional Expectation)

0 . Alomair, A. Malallah, A. Elsharkawy and M. Iqbal

983 > Towards the Development of Bitumen Carbonates: An Integrated Analysis of Grosmont Steam Pilots

Vers le développement des carbonates bitumineux : une analyse intégrée des pilotes vapeur de Grosmont

C.C. Ezeuko, J. Wang, M.S. Kallos and I.D. Gates

1007> A Novel Model of Foam Flooding Considering Multi-Factors for Enhancing Oil Recovery

Un nouveau modèle d'injection de mousse considérant de multiples facteurs afin d'améliorer la récupération de pétrole

J. Wang, H. Liu, H. Zhang, G. Zhang, P. Liu and K. Sepehrnoori
1025> Testing of Snorre Field Foam Assisted Water Alternating Gas (FAWAG) Performance in New Foam Screening Model

Vérification des performances de la méthode FAWAG (Foam Assisted Water Alternating Gas) sur le champ de Snorre, en Norvège, avec un nouveau modèle de sélection des mousses

P. Spirov and S. Rudyk

\section{ASPHALTENES}

1035> Structural Study of Asphaltenes from Iranian Heavy Crude Oil Étude structurale d'asphaltènes de pétrole brut lourd iranien L. Davarpanah, F. Vahabzadeh and A. Dermanaki

$1051>$ Experimental Study and Mathematical Modeling of Asphaltene Deposition Mechanism in Core Samples

Étude expérimentale et modélisation mathématique du mécanisme de déposition d'asphaltène dans des carottes de forage

T. Jafari Behbahani, C. Ghotbi, V. Taghikhani and A. Shahrabadi

1075> Prediction of the Gas Injection Effect on the Asphaltene Phase Envelope Prévision Prévision de l'effet d'injection de gaz sur l'enveloppe de phase des asphaltènes P. Bahrami, R. Kharrat, S. Mahdavi and H. Firoozinia

\section{HYDRATES}

1087> Methane Hydrate Formation and Dissociation in the Presence of Silica Sand and Bentonite Clay

Formation et dissociation d'hydrates de méthane en présence de sable de silice et d'argile de bentonite

V. Kumar Saw, G. Udayabhanu, A. Mandal and S. Laik

$1101>$ Prediction of Mass Flow Rate in Supersonic Natural Gas Processing Prédiction du débit massique dans les applications de traitement supersonique du gaz naturel

C. Wen, X. Cao, Y. Yang and Y. Feng

$1111>$ Experimental Study on Hydrate Induction Time of Gas-Saturated Water-in-Oil Emulsion using a High-Pressure Flow Loop

Étude expérimentale sur le temps d'induction d'hydrate d'une émulsion eau-enhuile saturée en gaz en utilisant une boucle à circulation sous haute pression X.F. Lv, B.H. Shi, Y. Wang, Y.X. Tang, L.Y. Wang and J. Gong

1125> Hollow Silica: A Novel Material for Methane Storage La silice creuse : un nouveau matériau pour le stockage de méthane V.D. Chari, P.S.R. Prasad and S.R. Murthy 


\title{
Experimental Study on Hydrate Induction Time of Gas-Saturated Water-in-Oil Emulsion using a High-Pressure Flow Loop
}

\author{
X.F. Lv' ${ }^{1}$, B.H. Shi ${ }^{1}$, Y. Wang ${ }^{1}$, Y.X. Tang ${ }^{2}$, L.Y. Wang ${ }^{1}$ and J. Gong ${ }^{1 *}$ \\ ${ }^{\prime}$ Beijing key laboratory of Urban Oil and Gas Distribution Technology, China University of Petroleum (Beijing), Beijing 102249 - China \\ ${ }^{2}$ SINOPEC Luoyang Petrochemical Engineering Corporation, Luoyang 471003 - China \\ e-mail: ydgi@cup.edu.cn \\ * Corresponding author
}

\begin{abstract}
Hydrate is one of the critical precipitates which have to be controlled for subsea flow assurance. The induction time of hydrate is therefore a significant parameter. However, there have been few studies on the induction time of the natural gas hydrate formation in a flow loop system. Consequently, a series of experiments were firstly performed, including water, natural gas and Diesel oil, on the hydrate induction time under various conditions such as the supercooling and supersaturation degree, water cut, anti-agglomerant dosage, etc. The experiments were conducted in a high-pressure hydrate flow loop newly constructed in the China University of Petroleum (Beijing), and dedicated to flow assurance studies. Then, based on previous research, this study puts forward a method for induction time, which is characterized by clear definition, convenient measurement and good generality. Furthermore, we investigated the influences of the experimental parameters and analyzed the experimental phenomena for the hydrate induction time in a flowing system.
\end{abstract}

Résumé - Étude expérimentale sur le temps d'induction d'hydrate d'une émulsion eau-en-huile saturée en gaz en utilisant une boucle à circulation sous haute pression - Les hydrates font partie des principaux précipités qui doivent être contrôlés pour assurer le débit d'écoulement. Le temps d'induction des hydrates est donc un paramètre significatif. Toutefois, peu d'études ont été réalisées sur le temps d'induction de formation d'hydrates de gaz naturel dans un système à boucle de circulation. Par conséquent, une série d'expériences a tout d'abord été effectuée, comprenant de l'eau, du gaz naturel et du gasoil, pour évaluer le temps d'induction des hydrates dans différentes conditions, telles que le degré de surréfrigération et de sursaturation, le watercut, le dosage d'anti-agglomérants, etc. Les expériences ont été réalisées dans une boucle de circulation d'hydrates sous haute pression nouvellement réalisée à l'Université Chinoise du Pétrole (Beijing) et dédiée aux études de maintiens d'écoulements. Puis, sur la base de recherches précédentes, la présente étude met en avant une méthode pour évaluer le temps d'induction, qui est caractérisée par une définition claire, un système de mesure pratique et une bonne généralisation. En outre, nous avons étudié les influences de paramètres expérimentaux et analysé le phénomène expérimental pour le temps d'induction des hydrates dans un système à écoulement. 


\section{LIST OF SYMBOLS}

$t_{i} \quad$ Induction time

$V \quad$ System volume

$J \quad$ Hydrate nucleation rate

$\alpha \quad$ Proportional constant

$r \quad$ Power of the growth rate of the hydrate nuclei

$t_{e} \quad$ Time needed to reach an equilibrium state

$t_{t} \quad$ Required time for turbidity

$t_{g} \quad$ Required time for the critical hydrate nuclei to grow into visible crystals

$t_{n} \quad$ Required time to form the critical nuclei

$S \quad$ Supersaturation degree

A Kinetic parameters

$c \quad$ Shape parameter

$\sigma_{e f} \quad$ Effective specific surface energy

$\Delta \mu \quad$ Driving force for the nucleation

$k \quad$ Boltzmann constant

$G \quad$ Growth rate when the nuclei grow into visible crystals

$\beta \quad$ Crystalline volume fraction

$\alpha_{n} \quad$ Shape factor

$f_{g v} \quad$ Gas fugacity

$f_{e q} \quad$ Equilibrium fugacity

$\Delta T_{\text {sub }} \quad$ Supercooling degree

$T_{e q} \quad$ Three-phase equilibrium temperature

$T_{\text {exp }} \quad$ Temperature of the flowing fluid in the experimental system

\section{INTRODUCTION}

Since the first discovery of hydrate in the natural gas transmission lines in the 1930s (Sloan, 2005), hydrate formation and blockage in long deep-water pipelines have long been a problem for offshore petroleum production. As oil and gas production moves towards the deeper water, and the deep sea oil and gas gathering and transportation tend to adopt mixed-transport technology (Shi, 2012), the low temperature and high pressure conditions necessary for hydrate formation between natural gas and water are frequently satisfied in petroleum pipelines. Upon formation, hydrate accumulation and agglomeration ultimately form a plug, blocking the flow through the pipeline. It is costly and dangerous to remove these plugs in the pipeline, which will lead to a significant loss in the production (Sloan and Koh, 2008). Therefore, the formation mechanism of gas hydrate in a flowing system has become a focal point in the hydrate research field, in order to effectively inhibit or prevent the hydrate formation.
The formation process of the gas hydrate is similar to the crystallization process (Sloan and Koh, 2008), including the hydrate nucleation stage and the hydrate growth stage, in which meta-stable crystallization is mainly caused by supercooling and/or supersaturation. The stable hydrate crystal nuclei that exceed the critical dimensions can be formed in the hydrate nucleation stage; then, these stable nuclei grow to the solid state in the hydrate growth stage. There exists quite a period of time, before the burst and the rapid growth of the hydrate nuclei, during which the macroscopic characteristics of the system will not change significantly. This period is defined as the hydrate induction phenomenon, which can be described by the hydrate induction time.

In other words, the induction time reflects the latency time before the hydrate begins to grow massively and rapidly. A long induction time would allow transport of fluids through the pipelines without the hydrate formation in the system; while a shorter period of the induction time might lead to a pipeline plug. Accordingly, the induction time in gas hydrate crystallization is an important characteristic of the kinetics of the process. The induction time is a measure of the ability of a supersaturated system to remain in the state of meta-stability; it could also indicate safe operation for the submarine multiphase pipelines (here safe means there is no hydrate blockage). According to the research reported by Kashchiev and Firoozabadi (2003), Vysniauskas and Bishnoi (1983), and Englezos et al. (1987), the occurrence and significance of the induction time have been evidenced and recognized.

However, due to the high meta-stable state existing in the course of the hydrate reaction, and the infinitesimal phenomenon that involves thousands of molecules, hydrate nucleation can hardly be observed accurately through usual experimental methods and/or installations (Mullin, 1993). As a result, there has been some experimental research on the hydrate induction time in autoclave cell systems, but with their experimental data differing greatly from each other (Muller-Bongartz et al., 1992; Parent and Bishnoi, 1996; Bansal, 1994; Nerheim et al., 1994; Cingotti et al., 1999; Kelland et al., 2000). For example, Cingotti et al. (1999) observed that the distribution of induction time data was scattered in their experiments in clean conditions, and they designed a specific procedure (1st formation/dissociation/ 2nd formation) to increase the reproducibility of the induction time. It is undeniable that the nucleation is stochastic from a theoretical point of view, but with different experimental procedures and conditions, a narrower induction time distribution can be obtained.

Although this research has made some achievements in this field, there is still a demand for well-performing 
predictive theoretical models, or a unanimous definition/ measuring method for the hydrate induction time. Consequently, there are various definitions of the induction time in view of different experimental methods (Kashchiev, 2000; Kashchiev et al., 1991; Natarajan et al., 1994; Natarajan, 1993; Kashchiev and Firoozabadi, 2002a; Söhnel and Mullin, 1988; Christiansen and Sloan, 1995).

One of the definitions of the induction time started from the equilibrium state to the time point at which the first crystal nucleus, with the critical size and stable property, came into being (Kashchiev, 2000; Kashchiev et al., 1991; Natarajan et al., 1994). Based on this, Kashchiev (2000) proposed a mononuclear theory of gas hydrate nucleation and established a corresponding mathematical model for the mononuclear induction time:

$$
t_{i}=1 /(J V)
$$

where $t_{i}$ is the induction time in the mononuclear theory, and $V$ is the system volume. $J$ is the hydrate nucleation rate, i.e. the amount/number of the critical nuclei produced per unit time and volume.

However, Natarajan et al. (1994) argued that the induction time should be defined as the time period from the equilibrium state to the time point where a large number of critical nuclei (not the first one) formed. Also, they provided the determination method for a typical induction time based on gas consumption (Fig. I), and a corresponding mathematical model:

$$
t_{i}=\alpha / J^{r}
$$

with the induction time defined as:

$$
t_{i}=t_{t}-t_{e}-t_{g}
$$

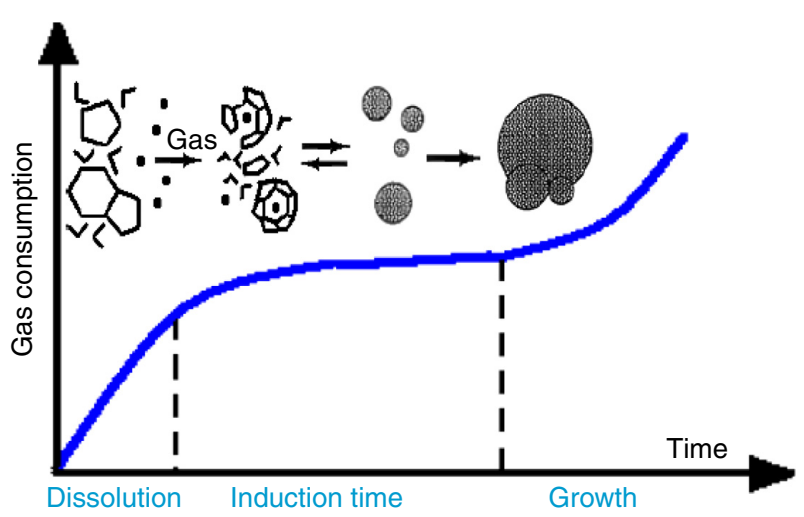

Figure 1

Typical gas consumption plots (Lederhos et al., 1996). where $\alpha$ is a proportional constant, and $r$ is the power of the growth rate $(J)$ of the hydrate nuclei. $t_{e}$ is the time needed to reach an equilibrium state for the system, and $t_{t}$ is the time needed for turbidity. $t_{g}$ is the required time for the critical hydrate nuclei to grow into visible crystals. At the same time, the experimental deviations are easily calculated from the determination of $t_{t}$ and $t_{g}$ in Equation (3).

Furthermore, Natarajan (1993) described the nucleation rate $J$ in Equation (2) using an empirical equation (Eq. 4), in which $J$ is a function of the supersaturation degree, according to the crystallization kinetics study (Mullin, 1993).

$$
J=k(S-1)^{n}
$$

where $k$ and $n$ are constants, and $S$ is the supersaturation degree.

Natarajan (1993) measured the induction time of gas hydrate crystallization. The result indicated that it could obtain repeatable data from either the structured water or unstructured water under relatively high pressure (>3.5 MPa). Kashchiev and Firoozabadi (2002a) derived an arithmetic expression ( $E q .5)$ for the hydrate nucleation rate through the analysis of nucleation kinetics of single-component gas hydrate in a rich aqueous solution:

$$
J=A e^{\frac{\Delta \mu}{k T}} \exp \left(-\frac{4 c^{3} v_{h}^{2} \sigma_{e f}^{3}}{27 k T \Delta^{2} \mu}\right)
$$

where $A$ is the kinetic parameters, and $c$ is the shape parameter. $v_{h}$ is the structure unit volume of hydrate. $\sigma_{e f}$ is the effective specific surface energy. $\Delta \mu$ is the driving force for the nucleation. $k$ is the Boltzmann constant.

In another definition, the induction time should be counted from the equilibrium state to the time point where plenty of visible crystals appear for the first time in a system (Mullin, 1993; Söhnel and Mullin, 1988). Kashchiev (2000) named this definition the polynuclear theory to distinguish it from mononuclear theory.

Söhnel and Mullin (1988) gave the expression of the induction time as:

$$
t_{i}=t_{n}+t_{g}
$$

where $t_{i}$ is the induction time in the polynuclear theory, and $t_{n}$ is the required time to form the critical nuclei.

Kashchiev et al. (1991) combined the mononuclear and polynuclear theories to generate an integrated model to calculate the induction time for the single-component gas hydrate:

$$
t_{i}=1 /(J V)+\left[\beta /\left(\alpha_{n} J G^{n-1}\right)\right]^{n}
$$


where $G$ is the growth rate when the nuclei grow into visible crystals. $\beta$ is the crystalline volume fraction and $\alpha_{n}$ is the shape factor.

However, Christiansen and Sloan (1995) derived another expression according to which the induction time is more sensitive to the growth rate than to the nucleation rate of the hydrate crystallites. They also proposed an empirical formula for the induction time $\left(t_{i}\right)$. The authors cautioned that this formula should not be used outside the range of the experimental data correlated by them.

Maeda et al. (2012) experimentally studied the induction time under different supercooling degrees, and obtained a longer induction time at the slower cooling rate.

In view of the fact that the aforementioned research was mainly conducted in autoclave cells under static or stirring conditions, Sun (2001) and Sun et al. (2004) fitted an empirical correlation (Eq. 8) of the induction time for methane hydrate in a flowing system. The experiments adopted the shielding ratio and pressure drop measurement method. The results showed that the hydrate induction time in a flowing system is not only related to pressure, but also to the flow velocity of the fluid:

$$
t_{i}=K\left(\frac{f_{g}^{v}}{f_{e q}} \sqrt{Q / Q_{0}}-1\right)^{-m}
$$

where $Q / Q_{0}$ is the mixing factor. $f_{g}^{v}$ is the gas fugacity (calculated by MRK EOS (Chen et al., 2000)). $f_{e q}$ is the equilibrium fugacity at the experimental temperature (calculated by the Chen-Guo hydrate model (Chen and Guo, 1996, 1998)).

Gainville and Sinquin (2011) researched the effect of the water cut, flow rate and flow regime on the induction time in the Lyre loop located at IFP Energies nouvelles Lyon. The experimental results indicated that the induction time was reduced with an increase in the water cut and flow rate, and the flow pattern's influence on the induction time was of great significance.

Gaillard (1996) researched the nucleation and growth of methane hydrate in a lab loop based both on crystallization theory and on measurements of gas consumption. The results indicated that the hydrate induction time in a flowing system relied on the influence of pressure, temperature and liquid velocity.

Turner (2005) defined the induction time for hydrate formation in the flow loop as the difference between the time that the loop temperature achieved the hydrate equilibrium temperature at the experimental pressure and the time of hydrate appearance (visual appearance of hydrate in the sight glasses, and a sudden shift in the particle size analyzer's total particle number registered were coincident and were interpreted at the point of hydrate appearance in the loop), and investigated the influence of the pump motor speed, water cut and fractions of gas on the induction time in an ExxonMobil flow loop. The experimental results showed that the induction time decreased as the impeller speed increased, but there was an exception to the general trend at the higher shear rates in all low gas fraction experiments. Meanwhile, no strong trend was apparent for the effect of the water cut on the flow loop induction time.

Therefore, the research on the induction time of multicomponent gas hydrate in an axial flow system is still at the experimental stage, which requires a lot of reliable experimental data so that the regularity of the hydrate induction time can be performed.

In summary, the existing definitions of the induction time can be classified from the microscopic view or the macroscopic view, respectively. Let the micro-view denote the definitions based on the critical nuclei; and the macro-view those according to the visible crystals. It can be found that these two measurement methods present different ranges for the induction time. In detail, the induction time ends at the critical nuclei's occurrence in the micro-view, while the broader induction time in the macro-view additionally covers the period from the critical nuclei to the visible crystals. However, it is hard to determine the critical nuclei uniformly under micro-view conditions owing to the diversity of the experimental equipment and/or measuring methods. Consequently, in view of the feasibility, there is limited applicability as well as uncertainty existing in the induction time in the micro-view; and the induction time in the macro-view still has major observation errors even with relatively easier determination.

Therefore, an explicit easily-measured definition of the hydrate induction time is proposed in this paper, which is applicable in an axial flow system. It is expected to supplement the studies in a flowing system with respect to the prevalent/current autoclave cells under static or stirring conditions in the majority. Meanwhile, the influencing factors of this defined induction time, i.e. the supersaturation/ supercooling degree, flow rate (disturbance), water cut, additive concentration, the geometry and size of the experimental loop, etc., were also investigated in the highpressure hydrate experimental loop.

\section{EXPERIMENTAL APPARATUS AND PROCEDURE}

\subsection{High-Pressure Hydrate Experimental Loop}

Experimental tests were carried out in the high-pressure hydrate experimental loop for Flow Assurance 
studies (Fig. 2). Natural gas and the liquid phase are injected separately by a plunger compressor $\left(2200 \mathrm{Nm}^{3} / \mathrm{h}\right)$ and a custom-made magnetic pump (flow rate up to $12 \mathrm{~m}^{3} / \mathrm{h}$ ) into the loop. It should be noted here that the physical interaction of the magnetic pump with the hydrate particles still cannot be quantitatively characterized due to its complication in the present experimental conditions; and if the particles are smaller than the clearance of the pump, the particles should not be affected by the pump.

Two sight glasses sit in the test sections. The gas injection point is the test section inlet. At the outlet of the test section, gas and liquid are collected in an insulated separator and are redirected toward the test section compressor (from the upper part) and pump (from the bottom), respectively. Several tanks allow maintenance of the loop and separator pressure as hydrate forms.

The 30-m stainless steel test section consisted of two rectilinear horizontal lengths joined together to form a pipe with $2.54 \mathrm{~cm}$ (1 inch) internal diameter, and a $5.08-\mathrm{cm}$ (2-inch)-diameter jacket circulating a waterglycol blend surrounded the test section. The process temperature control ranged from $-20^{\circ}$ to $100^{\circ} \mathrm{C}$.

\subsection{The Hydrate Experimental Loop Instrumentation}

This experimental flow loop is equipped with several sensors. Thermocouples are regularly set along the pipe, inside the separator, inside the water/glycol system and on the different gas utilities. A Coriolis flowmeter measures the density of the liquid mixture and the flow rate. The mean density of the multiphase fluid can also be measured using two FM1000 gamma ray densitometers. Differential pressure sensors are located along the loop to follow the evolution of the linear pressure drop along the loop. Rapid data acquisition is used to detect rapid phenomena.

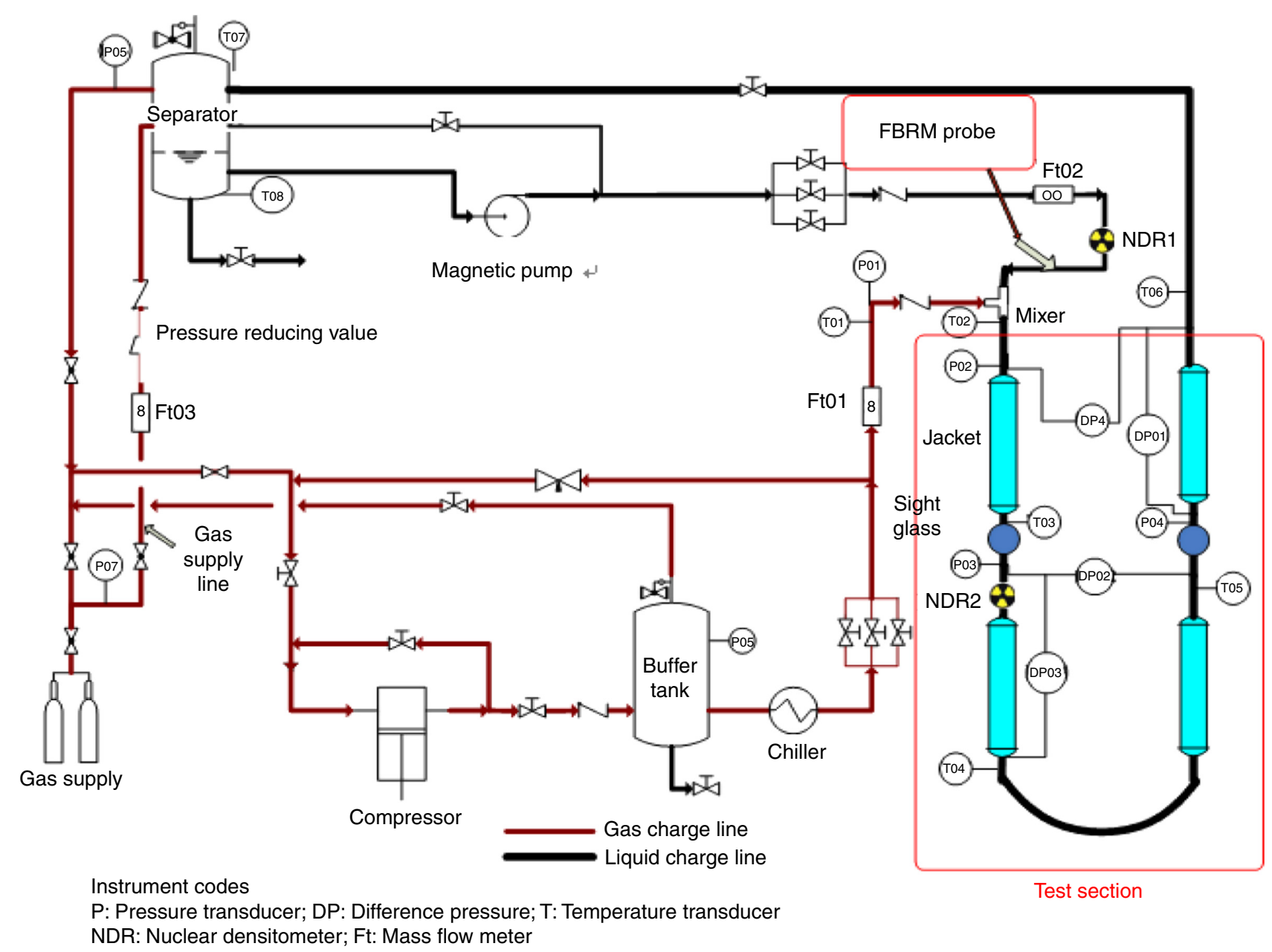

Figure 2

Schematic of the high-pressure hydrate experimental loop. 


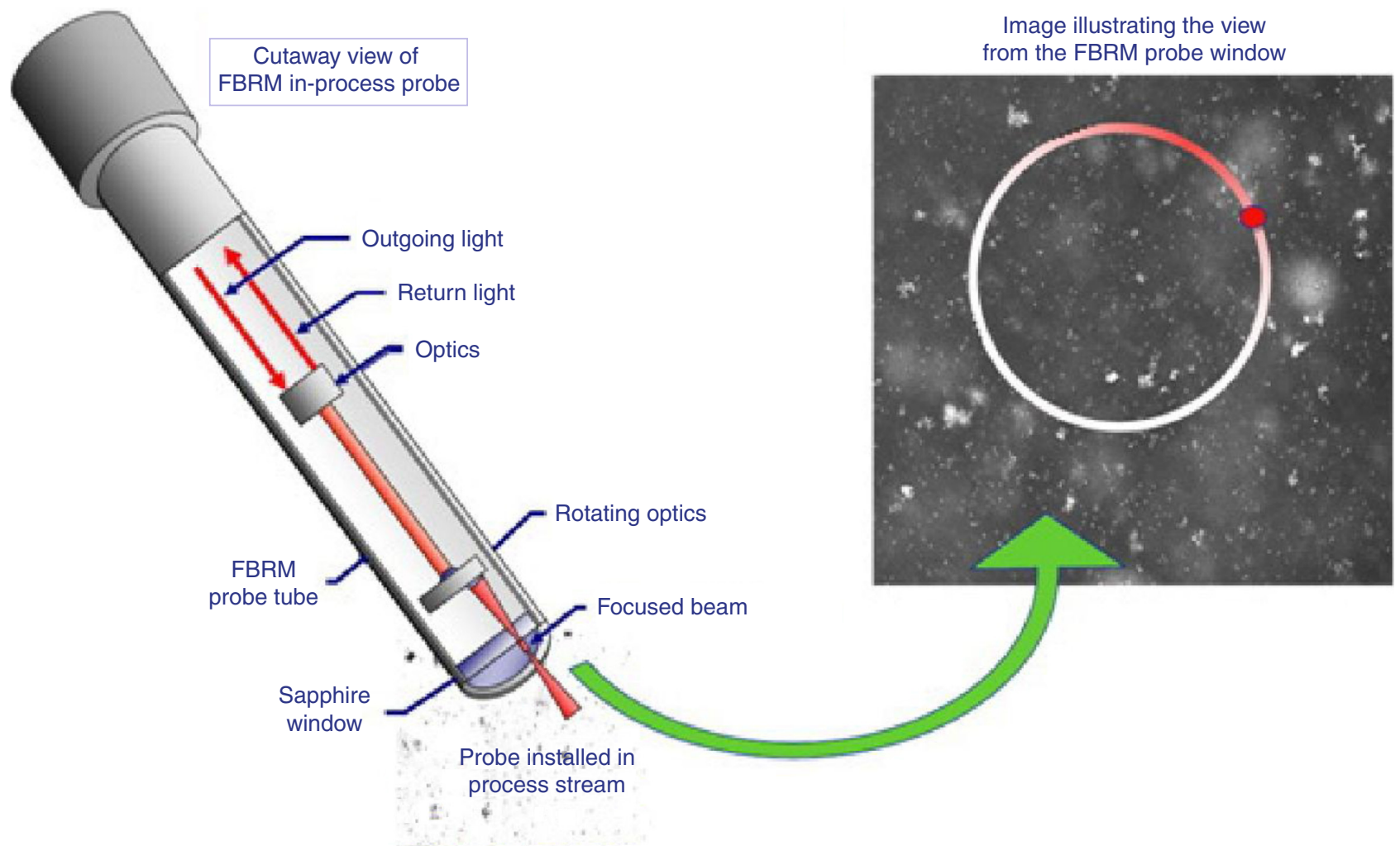

Figure 3

Principle of the FBRM particle size analyzer.

TABLE 1

The composition of gas samples $(\mathrm{mol} \%)$

\begin{tabular}{c|c|c|c}
\hline Composition & $\mathrm{Mol} \%$ & Composition & $\mathrm{Mol} \%$ \\
\hline $\mathrm{N}_{2}$ & 1.53 & $\mathrm{C}_{3}$ & 3.06 \\
\hline $\mathrm{CO}$ & 2.05 & $i \mathrm{C}_{4}$ & 0.33 \\
\hline $\mathrm{CO}_{2}$ & 0.89 & $i \mathrm{C}_{5}$ & 0.04 \\
\hline $\mathrm{C}_{1}$ & 89.02 & $n \mathrm{C}_{6}+$ & 0.01 \\
\hline $\mathrm{C}_{2}$ & 3.07 & - & - \\
\hline
\end{tabular}

A Focused Beam Reflectance Measurements (FBRM) probe (Mettler Toledo Company) which was installed on the loop, with a measurement range from $0.5 \sim 1000 \mu \mathrm{m}$, measured the evolution of objects (droplets, bubbles and solid particles) carried inside the flow. This apparatus comprises a low-intensity rotating LASER beam (Fig. 3) which is reflected when intercepting a particle. From the reflection time a chord length is deduced. A Chord Length Distribution (CLD) and a mean chord length are given every $10 \mathrm{~s}$. This CLD gives the chord length evolution versus time of the objects carried by the flow. As recommended for a representative sampling of the particle size distribution, this
TABLE 2

The composition of -20 \# Diesel oil

\begin{tabular}{c|c|c|c}
\hline Composition & Mol\% & Composition & Mol\% \\
\hline $\mathrm{C}_{11}$ & 0.89 & $\mathrm{C}_{16}$ & 6.83 \\
\hline $\mathrm{C}_{12}$ & 3.36 & $\mathrm{C}_{17}$ & 7.99 \\
\hline $\mathrm{C}_{13}$ & 5.38 & $\mathrm{C}_{18}$ & 7.46 \\
\hline $\mathrm{C}_{14}$ & 6.2 & $\mathrm{C}_{19}$ & 6.38 \\
\hline $\mathrm{C}_{15}$ & 6.78 & $\mathrm{C}_{20}+$ & 48.73 \\
\hline
\end{tabular}

particle size analyzer was installed on the straight vertical pipe which is ahead of the inlet of the experimental loop. The probe window cuts the flow streamlines at an angle of $45^{\circ}$ and reaches the center of the pipe. The FBRM probe was used to estimate the initial water droplet $(D p)$ size inside the fluid and to follow the hydrate particle agglomeration with time.

\subsection{Fluid}

Testing used deionized water, civil natural gas and -20\# Diesel (Tab. 1, 2). The Anti-Agglomerants (AA) are a 


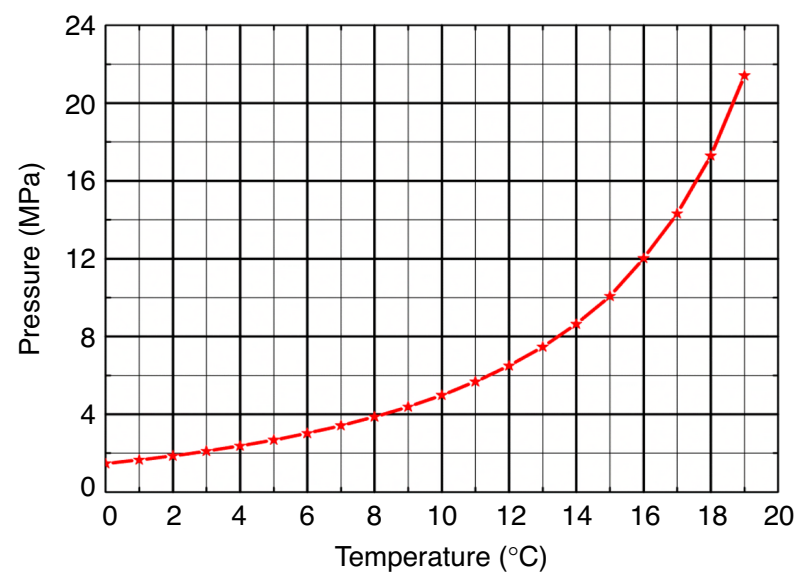

Figure 4

Hydrate formation curve of test natural gas.

formulation of some polymers and surfactants, which can be used in the water and oil mixture to form a $\mathrm{W} / \mathrm{O}$ emulsion where the water is dispersed as droplets in the oil phase. In this sense, the added AA are chemicals that are designed to allow hydrate formation but prevent adhesion of hydrate particles to each other. The AA (Chen et al., 2011) used in this work are from the China University of Petroleum's (Beijing) hydrate research laboratory of the College of Chemical Engineering.

An electronic balance weighed the quantity of AA (decrement method), with a measuring error of $\pm 0.01 \mathrm{~g}$, which is calculated according to various water cut situations. A high-pressure piston pump is used to inject the AA into the flow system. The preliminary Chen-Guo model (Chen and Guo, 1996, 1998) determined the curve of hydrate formation (Fig. 4) for the defined natural gas composition.

\subsection{Test Protocol}

1. The entire experimental loop is vacuumed until the vacuum degree reaches 0.9 bar;

2. The loop is loaded with Diesel and water (100 vol\% liquid loading) considering the set water cut for each test. Here, water cut is defined as the volume fraction/ratio of water to the loading liquid (Diesel + water), with the fixed Diesel volume being $70 \mathrm{~L}$ during all these experiments. The gas-supply unit begins to inject gas into the separator at room temperature $\left(20^{\circ} \mathrm{C}\right)$ until achieving the required experimental pressure (4, 5 and $6 \mathrm{MPa}$ in this paper);

3. The water and oil mixture is circulated at a constant flow rate to form a stable emulsion with the set AA dosage for each test. The stability of the water/oil emulsion referred to a relatively stable process (dynamic stability) according to the measured data from FBRM under shearing action. This is to say that the emulsion was regarded as stable when the average chord length of droplets fluctuated by $\pm 0.2 \mu \mathrm{m}$ within 2 hours;

4. Under the initial pressure and flow velocity, the temperature gradually decreases to the set value. During the hydrate formation process, a data acquisition system continuously collects the temperature, pressure, pressure drop, flow rate, density and chord length;

5. A round of experiments finishes at the end of the formation process when all measured data are stable, such as the system pressure and temperature. The dissociation of hydrate is carried out by increasing the temperature up to $30^{\circ} \mathrm{C}$. The system is kept in these conditions for 24 hours with the aid of the particle size analyzer preparing for the next round.

\section{RESULTS AND DISCUSSION}

Currently, the majority of studies of the hydrate induction period typically performed with autoclave cells are either under static or stirring conditions (Bansal, 1994; Nerheim et al., 1994; Cingotti et al., 1999; Kelland et al., 2000); relatively speaking, there is fewer research carried out in axial flow systems (Sun, 2001; Sun et al., 2004; Gainville and Sinquin, 2011; Gaillard, 1996; Gaillard et al., 1996; Turner, 2005; Sarshar et al., 2010). Consequently, an explicit general method, which is easy to adopt in field measurement, used to delimitate the induction time is proposed according to the combination of previous research and the hydrate slurry flow experiments in this work.

Based on the macro-concept, this method for the induction time defines a start point (an unanimous timing point) and an end point where the hydrate formation can be easily observed; the start point thereof should be typical as well as universal for one system or one process. Therefore, the time point when the system temperature dropped to the equilibrium temperature of the hydrate formation denotes the start point $\left(t_{s}\right)$ for the system in this paper, while the end point $\left(t_{e}\right)$ is the time point where the system temperature was about to rise due to the massive hydrate formation, as illustrated in Figure 5. It can therefore be perceived that this definition of the hydrate induction time involves both the process of hydrate nucleation and the growth stage of hydrate. All the influencing factors of both hydrate nucleation (Natarajan et al., 1994; Lederhos et al., 1996; Natarajan, 1993; Kashchiev and Firoozabadi, 2002a) and hydrate growth (Kashchiev et al., 1991) would thus affect this defined hydrate induction time. 


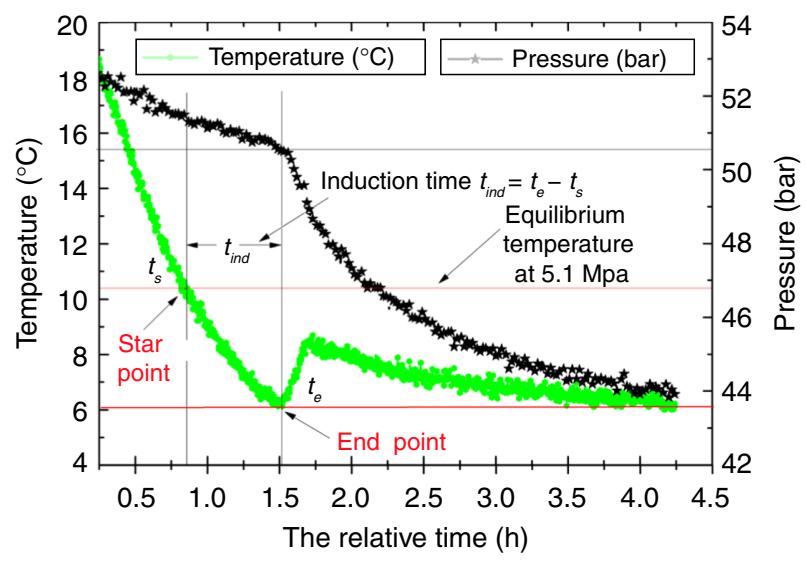

Figure 5

The definition method of the hydrate induction time.

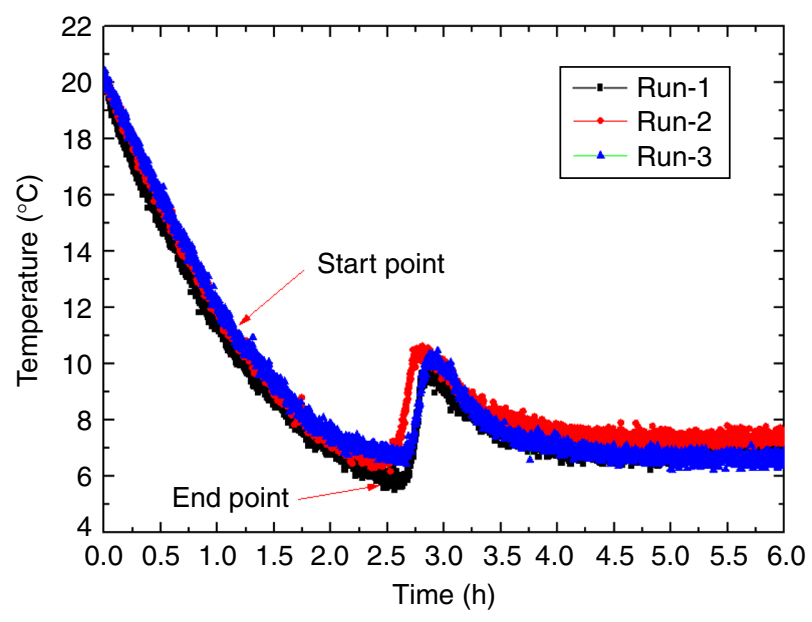

Figure 6

Natural gas induction time during three reproduced formation experiments in the flow loop $(4.7 \mathrm{MPa}, 0.8 \mathrm{~m} / \mathrm{s})$.

The flow loop experiment was performed three times to determine the reproducibility of the natural gas hydrate induction time defined in this paper, as shown in Figure 6. Induction time was remarkably reproducible at $1.6 \pm 0.1 \mathrm{~h}$.

\subsection{The Influence of the Supercooling Degree on the Induction Time}

The supercooling degree $\left(\Delta T_{\text {sub }}\right)$ is the difference between the three-phase equilibrium temperature $\left(T_{e q}\right)$ in the experimental conditions and the temperature of the flowing fluid $\left(T_{\text {exp }}\right)$ in the experimental system, i.e. $\Delta T_{\text {sub }}=T_{e q}-T_{\text {exp }}$.

Hydrate induction time was investigated under the conditions of gradually cooling and depressurization in the paper. These isochoric experiments are different from the reported isobaric/isothermal ones in the literature (Skovborg et al., 1993), which was meant to simulate the actual conditions of the deep-water pipeline transportation. Therefore, the supercooling degree in this paper is defined as the difference between the thermodynamic equilibrium temperature corresponding to the average system pressure before hydrate formation and the temperature bottom point which was about to rise owing to the hydrate formation, i.e. the temperatures corresponding to the $t_{s}$ and $t_{e}$ points in Figure 5, respectively. There has been research considering the hydrate supercooling degree under isobaric/isothermal conditions.

Skovborg et al. (1993) found under various experimental conditions that the hydrate induction time has an exponent relation with the supercooling degree at a relatively larger subcooling degree. More specifically, the larger the supercooling degree, the shorter the induction time will be. The main reason for this phenomenon is that the greater subcooling degree would lead to a more regular structure of water molecules (Sloan and Koh, 2008), then the faster growth rate of hydrate nuclei, thus the shorter hydrate induction time.

The hydrate flowing experiments with the Diesel + water + natural gas system in this work (Fig. 7,8) showed a similar experimental law to that of Skovborg et al. (1993) with respect to the influence of the supercooling degree on the induction time. It can be seen from Figure 7 that the hydrate induction time decreases with the increasing supercooling degree at both $1200 \mathrm{~kg} / \mathrm{h}$ and $1500 \mathrm{~kg} / \mathrm{h}$ flow rates, under the $4 \mathrm{MPa}$ system pressure. Similarly, the variation trend of the hydrate induction time could be observed at $1200 \mathrm{~kg} / \mathrm{h}, 1500 \mathrm{~kg} / \mathrm{h}$ and $1820 \mathrm{~kg} / \mathrm{h}$ flow rates, under $5 \mathrm{MPa}$ system pressure (Fig. 8).

Meanwhile, it can also be seen from Figures 7 and 8 that the induction time increases with the increasing flow rate in the same supercooling conditions. This also revealed the influence of the flow rate on the cooling effect in an axial flowing system. In detail, the relatively higher flow rate extended the hydrate induction time in several ways, such as generating heat from the friction, decreasing the heat exchange efficiency, etc. The overall results showed that the hydrate induction time in a flowing system is not only related to the supercooling degree, but also to the flow velocity of the fluid. It should be noted that the variation trend of induction time with the flow rate in this paper is different from the result of Sun (2001) and Sun et al. (2004). 


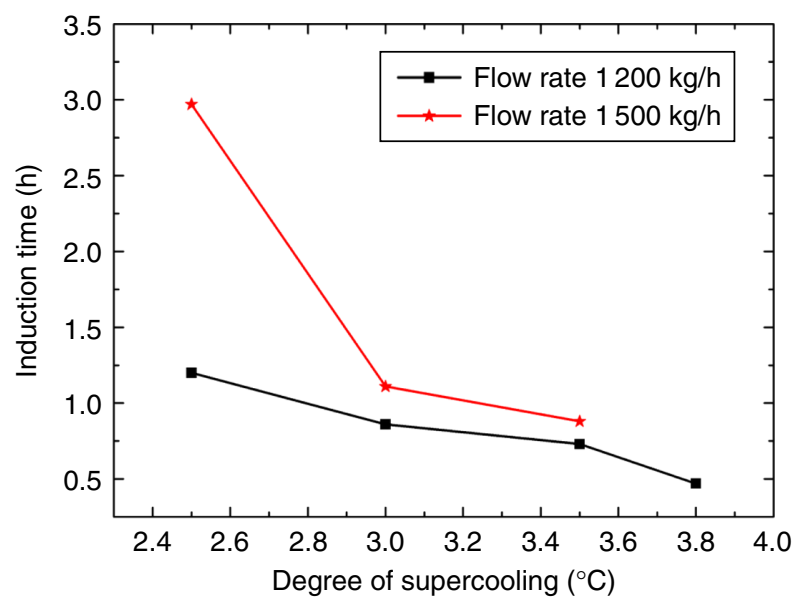

Figure 7

The influence of the supercooling degree on the hydrate induction time (4 MPa).

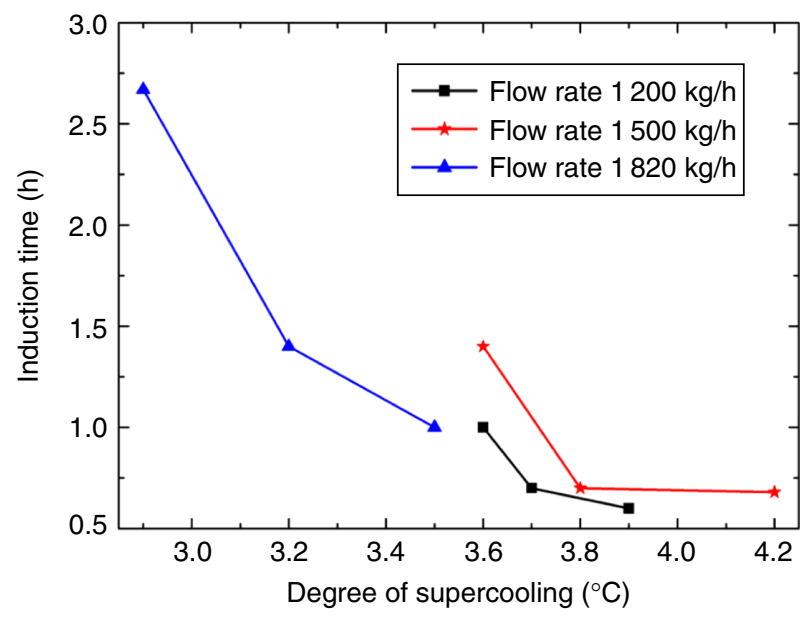

Figure 8

The influence of the supercooling degree on the hydrate induction time (5 $\mathrm{MPa})$.

\subsection{The Influence of the Supersaturation Degree on the Induction Time}

The term "supersaturation" is used for the driving force that induces hydrate formation. In the current literature, supersaturation has been expressed in many forms, such as the ratio of system pressure to equilibrium pressure, $S_{P}=P / P_{e q}$ (Herri et al., 1999) and the system to equilibrium fugacity ratio, $S_{f}=f / f_{e q}$ (Natarajan, 1993). Other supersaturations could be conceived to include the ratio of system to equilibrium hydrate former concentrations $\left(S_{C}=C / C_{e q}\right)$ or chemical potentials (Kashchiev and
Firoozabadi, 2002a) $\left(S_{\mu}=\mu / \mu_{e q}\right)$. Each of the supersaturation types above are defined to equal unity in equilibrium conditions.

Similar to the definition of the supercooling degree in Section 2.1, supersaturation has been defined as the ratio of the experimental equilibrium pressure (at the time point $t_{s}$ ) in the cooling process to the equilibrium pressure of the hydrate formation point, i.e. the ratio between the equilibrium pressure at the time point $t s$ and the corresponding equilibrium pressure of $t_{e}$ (experimental temperature) in Figure 5.

Kashchiev and Firoozabadi (2002b, 2003) considered that the hydrate induction time decreases significantly with the increasing supersaturation degree. Turner (2005) confirmed this conclusion that there is an inverse relationship between the hydrate induction time and the supersaturation degree. The interpretation of this phenomenon in the autoclave experiments is that the larger supersaturation degree enhances the driving force of hydrate nucleation, and thus speeds up the hydrate nucleation rate and shortens the hydrate induction time. This paper studied the influence of the supersaturation degree on the hydrate induction time in an axial flow system (Fig. 9, 10).

As shown in Figure 9, the induction time decreases generally as the supersaturation degree increases at the flow rates of $1200 \mathrm{~kg} / \mathrm{h}$ and $1500 \mathrm{~kg} / \mathrm{h}$. The exception that the induction time increases with the supersaturation degree at the $1820 \mathrm{~kg} / \mathrm{h}$ flow rate differs from the known experimental laws derived from the autoclave experiments. In Figure 10, the tendency of the induction time curve at the $1200 \mathrm{~kg} / \mathrm{h}$ flow rate agrees with that in an autoclave still, while the curves present a v shape (first decrease and then increase) at both the $1500 \mathrm{~kg} / \mathrm{h}$ and the $1820 \mathrm{~kg} / \mathrm{h}$ flow rates.

The research achievements of the following researchers could provide a reference for interpretation of the experimental phenomena. For instance, Makogon (1981) reported that the rate of formation of the methane hydrate nuclei increased with the subcooling degree and it presented a maximum value at a $\Delta T_{s u b}=2 \mathrm{~K}$. Gaillard et al. (1999) also found that the methane hydrate growth rate presented a maximum value that depended on the following parameters: the nature of the liquid phase, water/hydrocarbon condensate mixtures, flow velocity in the loop and the strongly correlated temperaturepressure subcooling variables.

Therefore, combined with the experimental law stemming from the autoclave, flow loop, and the actual operating conditions of the experiments in this work, the phenomenon that the hydrate induction time increases with the increasing supersaturation degree at relatively higher flow rates could be explained as follows: 


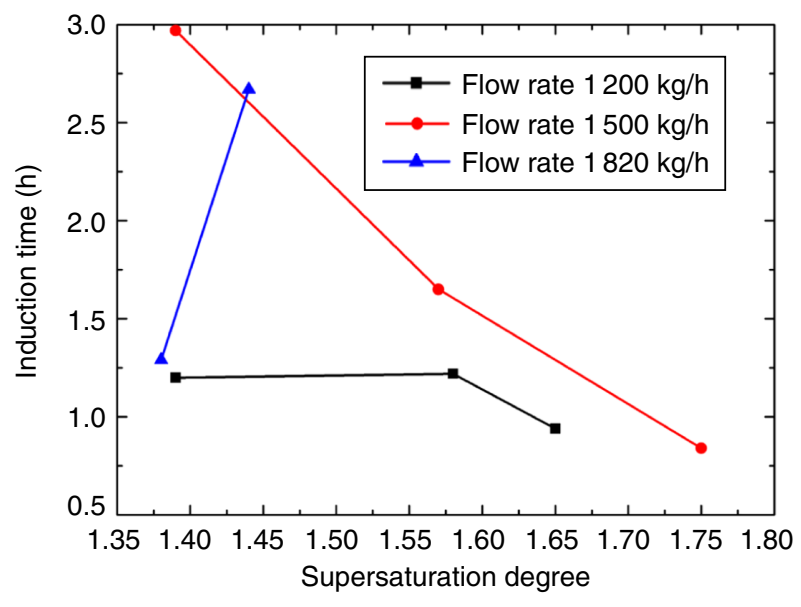

Figure 9

The influence of the supersaturation degree on the hydrate induction time $\left(4^{\circ} \mathrm{C}\right.$ temperature control).

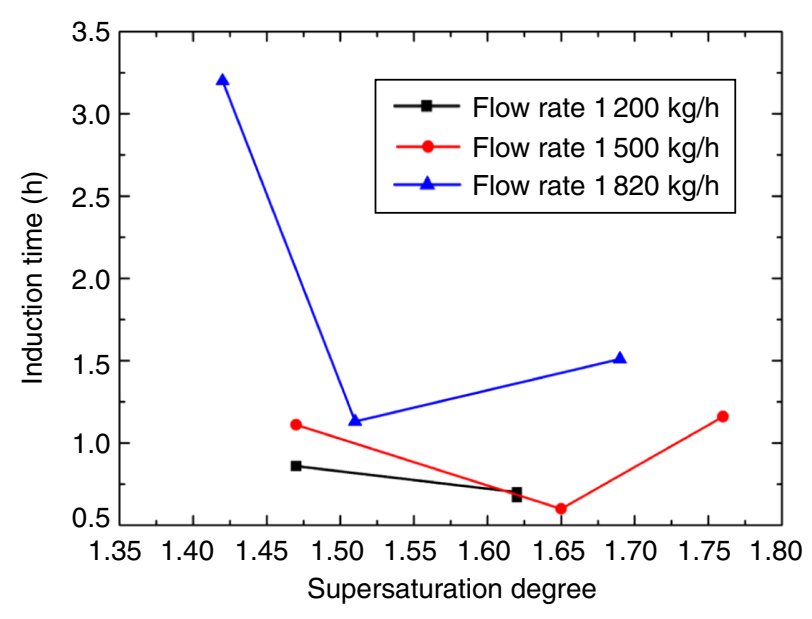

Figure 10

The influence of the supersaturation degree on the hydrate induction time $\left(2^{\circ} \mathrm{C}\right.$ temperature control).

1. On one hand, the larger supersaturation degree enhances the driving force of the mass transfer, and facilitates the hydrate nucleation and growth. It raises the temperature at which the hydrate begins to form, however, which accordingly reduces the supercooling degree, weakens the structure of the water molecules (Sloan and Koh, 2008), and prolongs the induction time of hydrates in the system;

2. On the other hand, the enhanced shearing action at relatively higher flow rates forms a more distributed emulsion; however, the higher flow rate increases the flow friction (generated heat), and weakens the cooling effect from the temperature-control system, suppressing the hydrate nucleation and growth in this axial flow system. This extends the hydrate induction time as well.

Moreover, the external temperature control setting of the experimental loop influences the induction time to some extent. The combination of the above two interpretations could lead to the phenomenon that the hydrate induction time extends with an increasing supersaturation degree at relatively higher flow rates.

\subsection{The Influence of the Flow Rate on the Induction Time}

Perturbation is one of the important factors influencing the nucleation rate of the hydrates; thus it could affect the hydrate induction time to some extent. Englezos et al. (1987) found that the induction time changed significantly by changing only the stirring rate, keeping the other conditions fixed in a semi-batch stirred reactor. The induction time was in inverse proportion to the stirring rate $(300 \sim 450 \mathrm{RPM})$, i.e. the maximum stirring rate generated the shortest induction time in the experimental conditions. Jensen et al. (2008) studied the formation of propane hydrate with/without additives under different stirring rates, observing that high-speed stirring can distinctly shorten the hydrate induction time and facilitate the rate of formation. In addition, a similar law was extracted from the experiments of the methane induction time by Skovborg et al. (1993) (stirring rate from 200 to 380 RPM). Sun (2001) performed the experiments for the hydrate induction time in a $\left(\mathrm{R} 12+\mathrm{H}_{2} \mathrm{O}\right)$ system, and found that the flow rate of the liquid is crucial to the induction time under a certain pressure; that is, the higher flow rates can lead to a shorter hydrate induction time. Moreover, Turner (2005) concluded that the induction time of hydrate basically tends to diminish with the increasing Revolutions Per Minute (RPM) speed in both the autoclave still and the flow loop.

The probable reason for the above experimental phenomena might be that the higher stirring rate stands for enhanced disturbance intensity, and thus gives rise to a larger gas-water interfacial area. The larger interfacial area permits more gas to be in contact with the water phase so as to accelerate the hydrate nucleation rate. Thus, the induction time becomes shorter with respect to the higher concentration of gas in the liquid within a certain time. However, it needs to be further verified whether the above conclusion can be used as a universal principle under the existing stirring rate.

Therefore, a series of experiments focusing on the hydrate induction time were conducted in order to validate the regularity of the aforementioned phenomena in an axial flow system, including water, natural gas and 
Diesel oil. The influence of the flow rate on the hydrate induction time is shown in Figures 11 and 12.

As shown in Figure 11, the experimental rule is disparate from the prevailing one that the hydrate induction time would decrease remarkably with the increasing flow rate. Instead, the hydrate induction time reduces first then increases with the increasing flow rate. In detail, the induction time decreases in the flow rate range from $950 \mathrm{~kg} / \mathrm{h}$ to $1200 \mathrm{~kg} / \mathrm{h}$, and then increases progressively when the flow rate exceeds $1200 \mathrm{~kg} / \mathrm{h}$. This can also be deduced from Figure 12.

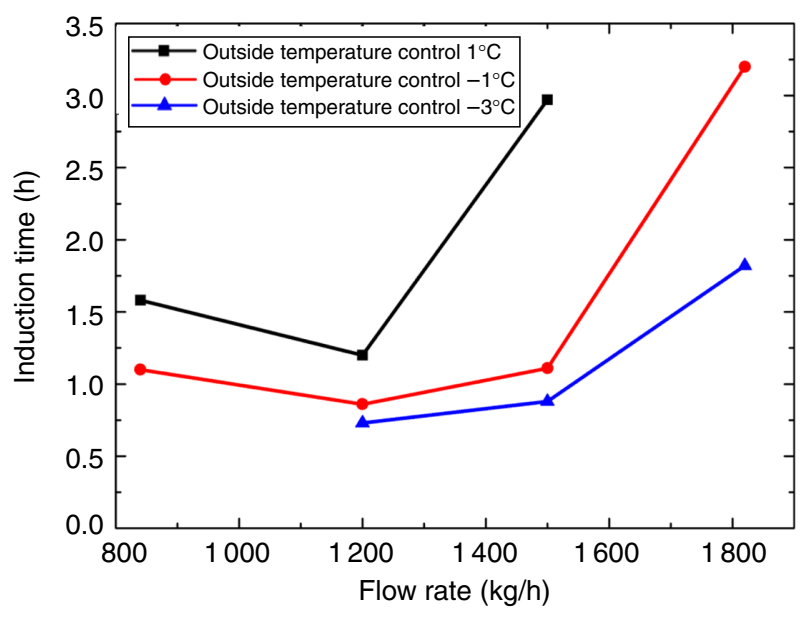

Figure 11

The influence of the flow rate on the hydrate induction time (4 MPa).

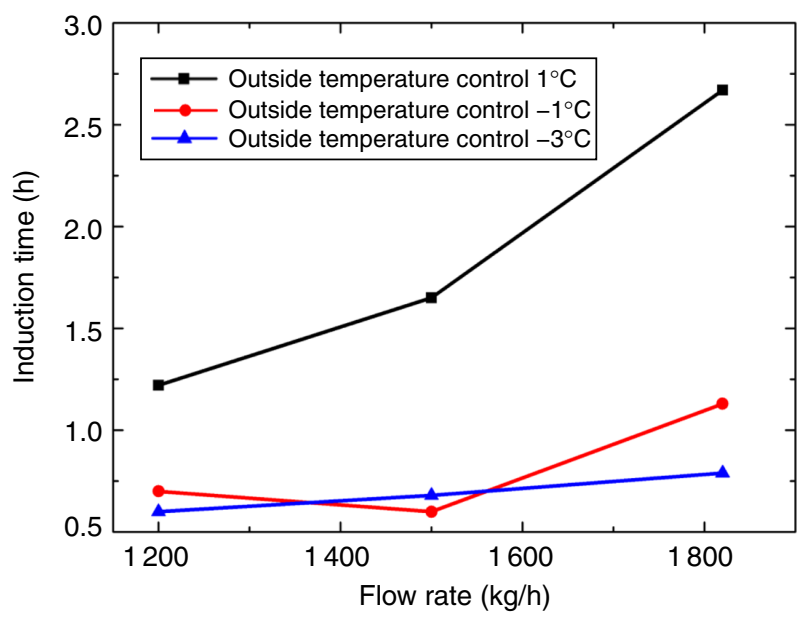

Figure 12

The influence of the flow rate on the hydrate induction time (5 MPa).
Firstly, the difference in the experimental apparatus and test protocols accounts for the disparate experimental phenomena to a certain degree. Secondly, the above phenomena can be mainly determined from the following two aspects:

1. The greater shearing action produced by the higher flow rate causes smaller water droplets, a larger contact area, and enhanced mass transfer by decreasing interfacial diffusion boundary layer thickness. So, the number of the nucleation sites increases, lessening the induction time of the hydrates. On one hand, the greater shearing action leads to a more uniform emulsion;

2. On the other hand, the greater flow rate brings about a higher friction pressure drop which raises the temperature of the fluids; it also reduces the cooling effect from the temperature-control system. Thus, it could extend the hydrate induction time.

The combination of these aspects results in the experimental phenomena presented in this work. It can be seen accordingly that the mass transfer between the guest molecules will significantly affect the hydrate induction time in the process of hydrate nucleation or formation. Therefore, the influence of the mass transfer on the hydrate induction time should be taken into consideration, with regard to the hydrate nucleation and growth process, which is dominated by the mass transfer.

\subsection{The Influence of the Water Cut on the Induction Time}

Turner (2005) studied the influence of the water cut on the hydrate induction time in the autoclave as well as the flow loop. The results indicated that the hydrate induction time decreased with the increasing water cut in the autoclave, while it changed little at various water cuts, i.e. the influence of the water cut was not obvious in an axial flow system.

The influence of the water cut on the hydrate induction time in this work is shown in Figure 13. Unlike the results obtained by Turner (2005), it can be seen that the induction time decreases first then increases with the increasing water cut during the experiments. The reasons for this difference are proposed as follows:

1. On one hand, the higher water cut produces a larger gas-water interfacial area (Fig. 14), leading to more nucleation sites and an accelerated nucleation rate;

2. On the other hand, the increased water cut could also result in the decreased gas solubility per unit volume of the oil-water emulsion. In the nucleation and growth 


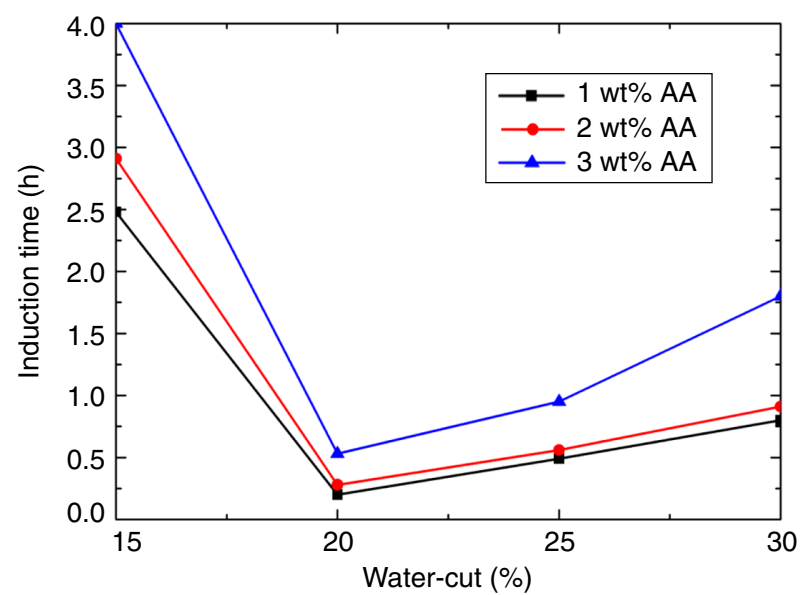

Figure 13

The influence of the water cut on the hydrate induction time.

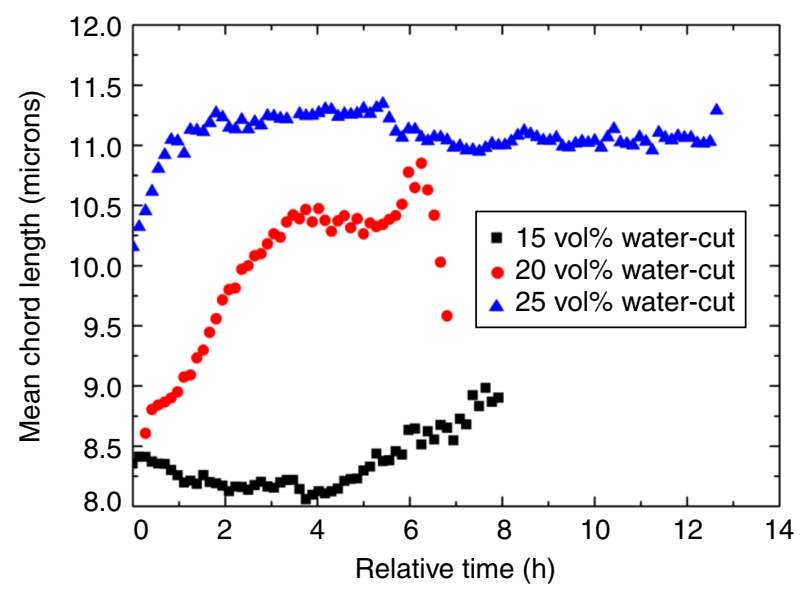

Figure 14

The influence of the water cut on chord length distribution (1.25 m/s flow velocity, $4 \mathrm{MPa}, 1 \mathrm{wt} \% \mathrm{AA})$.

process, the confined gas mass transfer decreases the nucleation and growth rate of the hydrates.

In general, the experimental phenomenon, that the hydrate induction time first decreases then increases with the increasing water cut, results from the combined impact of the above two explanations. It also proves that, in the hydrate formation process, the mass-transfer efficiency of the gas directly affects the formation of hydrates.

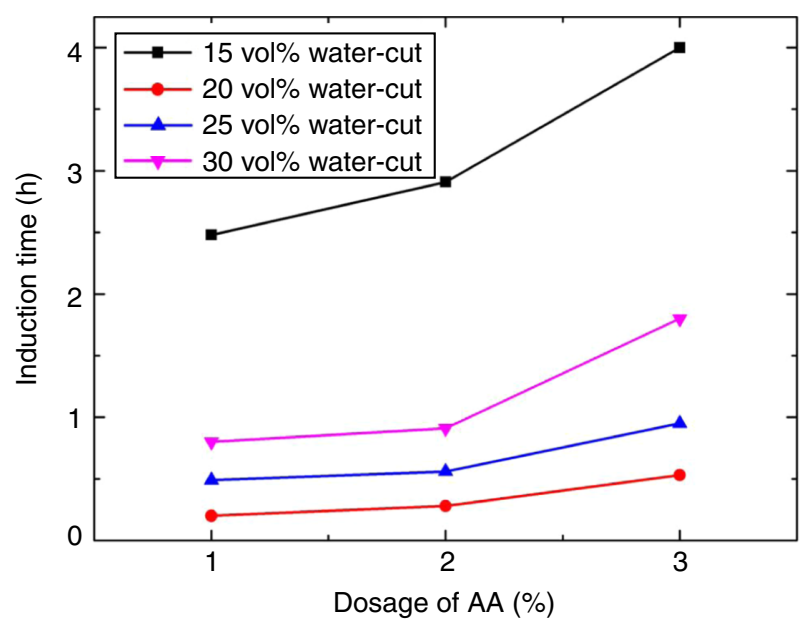

Figure 15

The influence of the AA concentration on the hydrate induction time.

\subsection{The Influence of AA Concentration on the Induction Time}

The AA (Peng, 2012) are a formulation of some polymers and surfactants, which can be used in the water and oil mixture to form a $\mathrm{W} / \mathrm{O}$ emulsion where the water is dispersed as droplets in the oil phase. In this sense, the added AA would allow hydrate formation but prevent adhesion of hydrate particles to each other. The result is supposedly hydrate slurry that flows without plugging.

Turner (2005) conducted experiments in a flow loop to investigate the influence of the AA concentration on the induction time. He concluded that the AA could not only prevent the aggregation between the hydrate particles, but also exhibited kinetic inhibitor behavior, delaying the hydrate induction time. Therefore, the hydrate induction time will be extended with increasing AA dosage. The experiments in this work confirmed this conclusion that enhanced AA concentration prolongs the hydrate induction time, as shown in Figure 15.

Figure 16 illustrated the inhibition effect of the AA on the hydrate nucleation and formation. As shown in Figure 15, the mean chord length of water droplets decreased with increasing AA dosage, which caused the larger contact area between water and oil phases. So, in the heterogeneous nucleation, the nucleation rate should be proportional to the interfacial area; however, this experimental result presented a different trend (Fig. 15). Therefore, the addition of the AA might not 


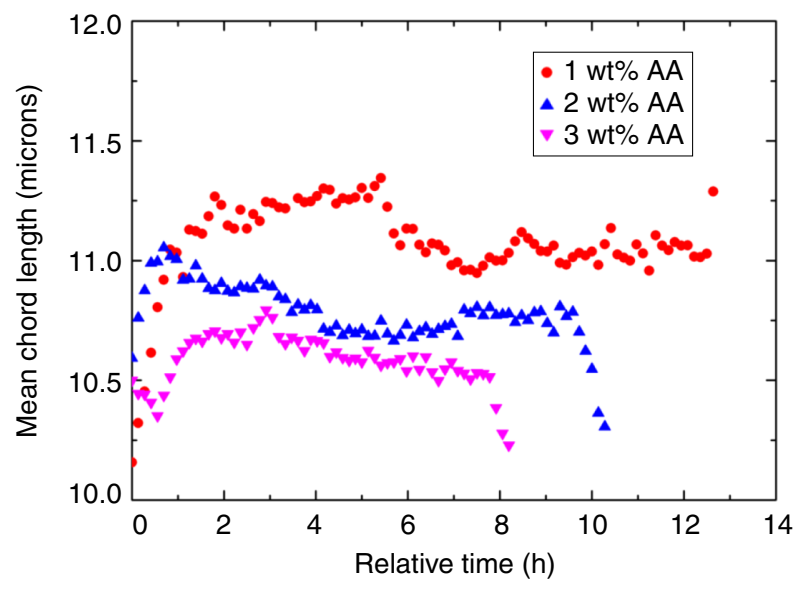

Figure 16

The influence of AA doses on chord length distribution ( $25 \mathrm{vol} \%$ water cut, $1.25 \mathrm{~m} / \mathrm{s}$ flow velocity, $4 \mathrm{MPa}$ ).

only restrain the agglomeration of the hydrate particles, but also play a role as a hydrate kinetic inhibitor.

\section{CONCLUSIONS}

1. The hydrate induction time decreases remarkably with the increasing supercooling degree in an axial flow system (an experimental loop in this paper), which is similar to the published experimental results conducted in the autoclave stills;

2. The variation tendency of the hydrate induction time along with the supersaturation degree in an axial flow system differs slightly from that in an autoclave still, i.e. the induction time would either present a v-shape curve or increase progressively with the increasing supersaturation degree at a relatively high flow rate. These phenomena could be construed as that the enhanced supersaturation degree reduces the structure of the water molecules and that the flow rate inhibits the hydrate nucleation and growth;

3. The hydrate induction time decreases first, and then increases (or gradually increases) with the increasing flow rate in the high-pressure flow loop;

4. There is a little discrepancy between the influence of the water cut on the hydrate induction time in this work and that in the literature. In other words, the hydrate induction time decreases first and then increases with the increasing water cut in these experiments;

5. The influence rule of the AA concentration resembles that in the literature; that is, an increased AA dose prolongs the hydrate induction time within a certain range.

\section{ACKNOWLEDGMENTS}

This paper was sponsored by the National Natural Science Foundation of China (51274218, 51306208 and 51134006), National Science \& Technology Specific Project (2011ZX05026-004-03), and Science Foundation of China University of Petroleum-Beijing (No. 2462013 YXBS010 and No. 2462014YJRC006).

\section{REFERENCES}

Bansal V. (1994) Kinetic Study of Clathrate Hydrates, MS Thesis, Colorado School of Mines, Golden, CO.

Christiansen R.L., Sloan E.D. (1995) Proceedings of the 74th Gas Processors Association Convention, San Antonio, TX, 13-15 March.

Chen G.J., Guo T.M. (1996) Thermodynamic Modeling of Hydrate Formation Based on New Concepts, Fluid Phase Equilibria 112, 43-65.

Chen G.J., Guo T.M. (1998) A New Approach to Gas Hydrate Modeling, Chemical Engineering Journal 71, 145-151.

Chen G.J., Li W.Z., Li Q.P., Sun C.Y., Mu L., Chen J., Peng B.Z., Yang Y.T., Meng H. (2011) China Patent Number 201110096579.2.

Chen G.J., Sun C.Y., Guo T.M. (2000) A Theoretical Revision of the Derivation of Liquid Property Expressions from an Equation of State and Its Application, Chemical Engineering Science 55, 4913-4923.

Cingotti B., Sinquin A., Pic J.S., Herri J.M., Cournil M. (1999) Proceedings SPE International Symposium on Oilfield Chemistry, Houston, TX, 16-19 Feb.

Englezos P., Kalogerakis N., Dholabhai P.D., Bishnoi P.R. (1987) Kinetics Formation of Methane and Ethane Gas Hydrates, Chemical Engineering Science 42, 11, 2647-2658.

Gaillard C.. (1996) Kinetic of Methane Hydrate Formation in a Lab Loop, PhD Thesis, Institut National Polytechnique de Toulouse, France.

Gaillard C., Monfort J.-P., Peytavy J. (1996) Formation and Growth Kinetics of Natural Gas Hydrate, The 2th International Conference on Gas Hydrates, Toulouse, France, 2-6 June.

Gaillard C., Monfort J.-P., Peytavy J.L. (1999) Investigation of Methane Hydrate Formation in a Recirculating Flow Loop: Modeling of the Kinetics and Tests of Efficiency of Chemical Additives on Hydrate Inhibition, Oil \& Gas Science and Technology - Rev. IFP 54, 3, 365-374.

Gainville M., Sinquin A. (2011) Hydrate Slurry Characterization for Laminar and Turbulent Flows in Pipelines, The 7th International Conference on Gas Hydrates, Edinburgh, Scotland, United Kingdom, 17-21 July.

Herri J.M., Pic J.S., Gruy F., Cournil M. (1999) Methane hydrate crystallization mechanism from in-situ particle sizing, AIChE Journal 45, 590-602.

Jensen L., Thomsen K., von Solms N. (2008) Propane hydrate nucleation: Experimental Investigation and Correlation, Chemical Engineering Science 63, 3069-3080.

Kashchiev D. (2000) Nucleation: Basic Theory with Application, Butterworth-Heineman, Oxford. 
Kashchiev D., Firoozabadi A. (2002a) Driving Force for Crystallization of Gas Hydrates, Journal of Crystal Growth 241, 220-230.

Kashchiev D., Firoozabadi A. (2002b) Nucleation of Gas Hydrates, Journal of Crystal Growth 243, 476-489.

Kashchiev D., Firoozabadi A. (2003) Induction Time in Crystallization of Gas Hydrates, Journal of Crystal Growth 250, 499-515.

Kashchiev D., Verdoes D., Von Rosmalen G.M. (1991) Induction Time and Metastability Limit in New Phase Formation, Journal of Crystal Growth 110, 373-380.

Kelland M., Svartaas T., Ovsthus J., Namba T. (2000) A new Class of Kinetic inhibitor, Annals of the New York Academy of Sciences, New York, January.

Lederhos J.P., Long J.P., Sum A., Christiansen R.L., Sloan E.D. Jr (1996) Effective kinetic inhibitors for natural gas hydrates, Chemical Engineering Science 51, 8, 1221-1229.

Maeda N., Wells D., Hartley P.G., Kozielski K.A. (2012) Statistical Analysis of Supercooling in Fuel Gas Hydrate Systems, Energy \& Fuels 26, 1820-1827.

Makogon Y.F. (1981) Hydrates of Natural Gas, Penn Well Book, Tulsa, United States.

Muller-Bongartz B., Wildeman T.R., Sloan E.D. (1992) Proceedings Second International Offshore and Polar Engineering Conference, San Francisco, USA, 14-19 June.

Mullin J.W. (1993) Crystallization, 3rd Edition, ButterworthHeinmann, Oxford, UK.

Natarajan V. (1993) Thermodynamic and Nucleation Kinetics of Gas Hydrates, PhD Dissertation, University of Calgary, Calgary.

Natarajan V., Bishnoi P.R., Kalogerakis N. (1994) Induction Phenomena in Gas Hydrate Nucleation, Chemical Engineering Science 49, 2075-2087.

Nerheim A.R., Svartaas T.M., Samuelsen E.J. (1994) Proceedings Fourth International Offshore and Polar Engineering Conference, Osaka, Japan, 10-15 April.

Parent J.S., Bishnoi P. (1996) Investigations into the Nucleation Behavior of Methane Gas Hydrates, Chemical Engineering Communication 144, 51-64.
Peng B.Z. (2012) Study on Hydrate Slurry Transportation in Multi-phase Pipeline, PhD Dissertation, China University of Petroleum, Beijing.

Sarshar M., Smaeilzadeh F., Fathikalajahi J. (2010) Induction Time of Hydrate Formation in a Flow loop, Theoretical Foundations of Chemical Engineering 44, 201-205.

Shi B.H. (2012) Study on the Characteristics of Hydrate Growth and Flow in Gas-Condensate Multiphase Pipelines, PhD Dissertation, China University of Petroleum, Beijing.

Skovborg P., Ng H.J., Rasmussen P., Mohn U. (1993) Measurement of Induction Times for the Formation of Methane and Ethane Gas Hydrates, Chemical Engineering Science 48, 3, 445-453.

Sloan E.D. (2005) A Changing Hydrate Paradigm-from Apprehension to Avoidance to Risk Management, Fluid Phase Equilibra 228-229, 67-74.

Sloan E.D., Koh C.A. (2008) Clathrate Hydrates of Natural Gas, 3rd Edition, CRC Press, Taylor \& Francis Group, Boca Raton, FL.

Sun C.Y. (2001) The Related Basic Research to the Development of Gas Mixtures Separation Technology by Forming Hydrate, PhD Dissertation, China University of Petroleum, Beijing.

Sun C.Y., Chen G.J., Yue G.L. (2004) The Induction Period of Hydrate Formation in Flow System, Chinese Journal Chemical Engineering 12, 527-531.

Söhnel O., Mullin J.W. (1988) Interpretation of Crystallization Induction Periods, Journal Colloid Interface Science 123, 43-50.

Turner D.J. (2005) Clathrate Hydrate Formation in Water-inoil Dispersions, PhD Dissertation, Colorado School of Mines, Colorado.

Vysniauskas A., Bishnoi P.R. (1983) A Kinetic Study of Methane Hydrate Formation, Chemical Engineering Science 38, 1061-1072.

Cite this article as: X.F. Lv, B.H. Shi, Y. Wang, Y.X. Tang, L.Y. Wang and J. Gong (2014). Experimental Study on Hydrate Induction Time of Gas-Saturated Water-in-Oil Emulsion using a High-Pressure Flow Loop, Oil Gas Sci. Technol 70,6, $1111-1124$. 